\title{
Babinski sign in the only existing sculpture by Leonardo
}

\author{
Francesco Brigo $^{1,2}$ (D) Francesco Caglioti $^{3}$
}

Received: 15 July 2019 / Accepted: 5 August 2019 / Published online: 9 August 2020

(C) Springer-Verlag GmbH Germany, part of Springer Nature 2019

\section{Background}

The extensor cutaneous plantar reflex is one of the most important signs in clinical neurology. Also known as Babinski sign, from the name of the French neurologist who first described it in 1896 (Joseph Jules François Félix Babinski, 1857-1932), it refers to the extension (dorsiflexion) of the big toe following stimulation of the sole of the foot in patients with damage to the central nervous system motor pathways [1]. In newborns and infants, the Babinski sign is considered a normal finding. However, with the maturation of the infant's nervous system, it disappears [1].

Several eminent painters of the past depicted this phenomenon in infants and young children [2], including the Florentine Sandro Botticelli (1445-1510) [3]. However, only two artists represented the Babinski sign involving both feet. The first was the Florentine Andrea del Verrocchio (1435 c.88) in his painting of "The Virgin and Child with Two Angels" (c. 1470) at the National Gallery, London. The other was Leonardo da Vinci (1452-1519), pupil of Verrocchio, in the "Madonna of the Carnation" (c. 1478) displayed at the Alte Pinakothek in Munich. In both paintings the Baby Jesus, seated on the Virgin's lap, has a bilateral extensor plantar reflex.

Very recently, a terracotta statuette representing the "Virgin with the Laughing Child" (c. 1472), belonging to the Victoria and Albert Museum in London (Fig. 1), has been fully

Francesco Brigo

dr.francescobrigo@gmail.com

1 Division of Neurology, "Franz Tappeiner" Hospital, Merano, Bolzano, Italy

2 Department of Neuroscience, Biomedicine and Movement Science, University of Verona, Piazzale L.A. Scuro, 10, 37134 Verona, Italy

3 Classe di Lettere e Filosofia, Scuola Normale Superiore, Piazza dei Cavalieri, 7, Pisa 56126, Italy attributed to Leonardo da Vinci $[4,5]$. In the London museum and in art historical literature, it has been constantly labelled, without the help of any comparison whatever, as a work of the 15th-Century Florentine sculptor Antonio Rossellino (1427/28-1479 c.), although some distinguished experts between 1899 and 1959 already realized that it should have been by Leonardo's hand. This rediscovery is indeed of outstanding relevance, as it makes this work the only surviving sculpture by Leonardo (not only a painter, but also a sculptor, like his master). Striking similarities between features of this statuette and many paintings and drawings by this much celebrated artist definitely dispel any doubts regarding the attribution [5].

Curiously, in this statuette the Baby Jesus shows a bilateral Babinski sign (Fig. 2 and Cover). This feature, so far overlooked, provides further evidence supporting the new attribution to Leonardo, since a bilateral Babinski sign is typically and exclusively encountered in the works of Verrocchio and Leonardo himself.

It might be tempting to speculate that Leonardo was aware of the dorsiflexion of the big toe as the physiological response of an infant to the stimulation of the sole. However, although this detail denotes an outstanding attention to natural phenomena, it does not mean that Leonardo understood its real meaning, as in the statuette the dorsiflexion of the great toes occurs without any foot sole stimulation. Hence, as observed in paintings by Botticelli, this anatomical detail "should be interpreted as a stylistic mannerism to which the artist liked to indulge" [3], with the aim of infusing a greater sense of vividness into the portrait of this laughing infant.

\section{Conclusion}

The depiction of a bilateral Babinski sign in this sculpture and in the other works mentioned above undoubtedly demonstrates the increasing interest of Renaissance artists towards a natural representation of the human body and their attempt to humanize sacred subjects, breaking away from the conventional human forms of the Middle Ages. 
Fig. 1 Leonardo da Vinci: "Virgin with the Laughing Child" (c. 1472). Victoria and Albert Museum, London. (C) Victoria and Albert Museum, London

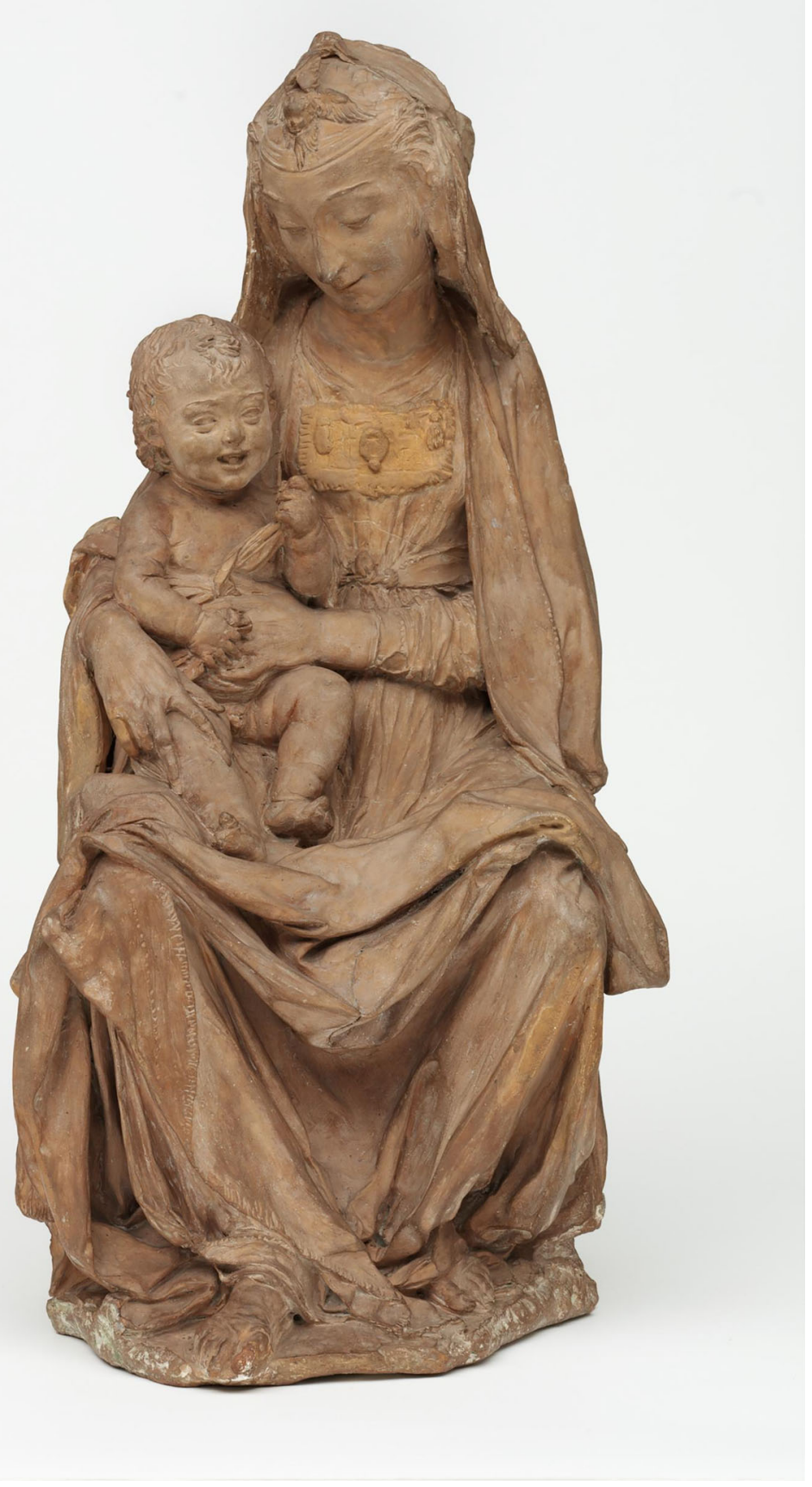




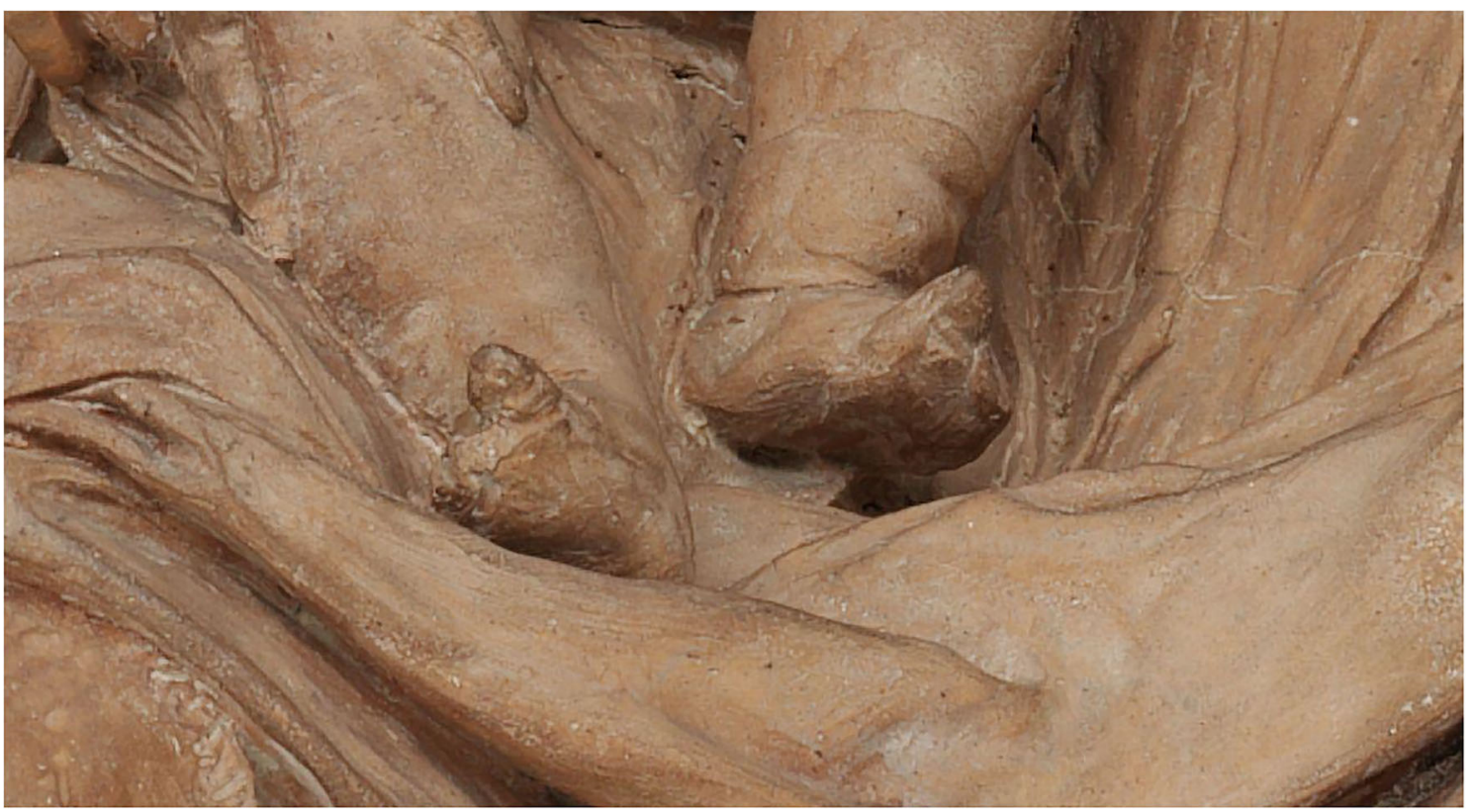

Fig. 2 and Cover Close-up of bilateral Babinski sign in the Baby Jesus. Victoria and Albert Museum, London. (C) Victoria and Albert Museum, London

Acknowledgements We thank Andrea Orioli for graphical support.

\section{Compliance with ethical standards}

Conflict of interest Francesco Brigo has acted as a paid consultant to Eisai, LivaNova, and UCB Pharma, and received travel support from Eisai. Francesco Caglioti is responsible for attributing the statuette to Leonardo da Vinci.

\section{References}

1. Ambesh P, Paliwal VK, Shetty V, Kamholz S (2017) The Babinski sign: a comprehensive review. J Neurol Sci 372:477-481
2. Massey EW, Sanders L (1989) Babinski's sign in medieval, renaissance, and baroque art. Arch Neurol 46:85-88

3. Di Rocco C (2006) Botticelli and the Babinski sign. Childs Nerv Syst 22:1061-1062

4. Caglioti F (2004) Matteo Civitali e il suo tempo. Pittori, scultori e orafi a Lucca nel tardo Quattrocento. Exh. cat. Silvana Editoriale, Cinisello Balsamo, 67, 71-72

5. Caglioti F (2019) Verrocchio, Master of Leonardo. Exh. cat. Marsilio, Venezia, 38-9, 45, 280-3

Publisher's note Springer Nature remains neutral with regard to jurisdictional claims in published maps and institutional affiliations. 